Schone

\section{energie, mooi}

landschap?

AUTEUR Renée de Waal en Sven Stremke

ILLUSTRATIES Sven Stremke, MVRDV \& Chang et al.

Door te erkennen dat fossiele brandstoffen eindig zijn en het verbranden ervan van invloed is op ons klimaat, zijn we genoodzaakt om na te denken over het post-fossiele tijdperk. De huidige energievoorziening moet aangepast worden naar een zuinig systeem dat gebaseerd is op hernieuwbare bronnen. Maar hoe gaan we dat doen, en hoe ziet ons landschap eruit als de energietransitie doorzet?

De nationale overheid streeft ernaar om in 202014 procent van ons energieverbruik uit duurzame energie te laten bestaan en 20 procent minder CO2 uit te stoten dan in het jaar 1990. Hiermee sluit Nederland aan op Europees beleid rond duurzame energie en het klimaat. De meest recente cijfers, uit 2009, tonen echter aan dat het aandeel duurzame energie nog geen 4 procent bedraagt, wat aangeeft dat Nederland lang niet op schema ligt.

$\mathrm{Er}$ is dus werk aan de winkel. Omdat de relatie tussen energie en ruimte zo sterk is, zijn ruimtelijke planning en ontwerp disciplines bij uitstek om energietransitie aan te pakken. Duurzame energie moet niet opgevat worden als een extra complicerende factor, maar als een kans voor ruimtelijke ontwikkelingen die een bijdrage kunnen leveren aan het verhogen van de kwaliteit en identiteit van het landschap. De huidige innovatieregeling 'Identiteit van energielandschappen' uit het programma 'Mooi Nederland' van het ministerie van Infrastructuur en Milieu neemt dit streven als uitgangspunt en ook de Eo Wijers-prijsvraag, één van de belangrijkste competities voor ruimtelijk ontwerp in Nederland, heeft in de editie 2011-2012 als thema 'Krimp, energietransitie en ruimtelijke kwaliteit'. In dit artikel wordt nader ingegaan op huidige ontwikkelingen binnen het energiebewust plannen en ontwerpen, en wordt er aan de hand van voorbeelden getoond hoe landschappelijke kwaliteit daarin een steeds belangrijkere rol inneemt.

\section{Energiebewust plannen en ontwerpen}

De 'Trias Energetica' is in het doorvoeren van energietransitie inmiddels een algemeen principe. Ten eerste moet het energieverbruik zoveel mogelijk gereduceerd worden, ten tweede moet zoveel mogelijk energie uit duurzame bronnen worden opgewekt en tot slot moeten fossiele brandstoffen die er nog zijn zo optimaal mogelijk worden ingezet. Onderzoek binnen de leerstoelgroep 'Landschapsarchitectuur' van de Wageningen Universiteit richt zich op energiebesparing en het duurzaam opwekken van energie op landschappelijke schaal. Er is aangetoond dat de wetten van de thermodynamica, maar ook concepten uit de ecologie en systeemwetenschap, aan de basis kunnen staan van strategieën voor energiebewust ruimtelijk plannen en ontwerpen. Hoe ruimtelijke ordening en landschapsarchitectuur bijvoorbeeld kunnen helpen in het realiseren van energiebesparing kan geïllustreerd worden met de volgende twee simpele strategieën

Figuur 1 laat zien dat energie-'sources' en 'sinks' dichter bij elkaar gepland zouden moeten worden. Door functies die energie over hebben dichtbij functies die juist energie nodig hebben te lokaliseren zijn ze makkelijker aan elkaar te koppelen. Daarmee wordt ook bespaard op warmte- en energieverlies als gevolg van lange transportafstanden.

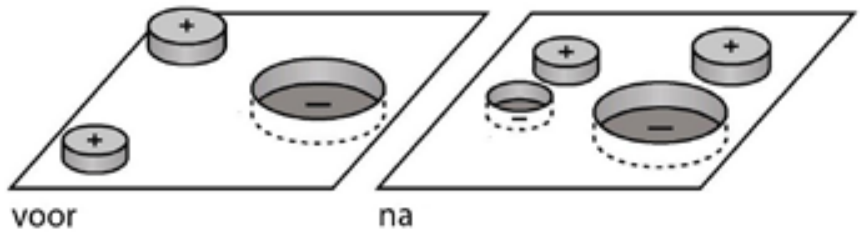

Figuur 1. Het lokaliseren van energie 'sources' en 'sinks' ten opzichte van elkaar

In figuur 2 is een warmtecascadering schematisch weergegeven. De grote cilinder met de ' + ' representeert een functie waarbij veel restwarmte vrijkomt, bijvoorbeeld een afvalverbrandingsinstallatie. Deze restwarmte kan direct over de volgende gebruikers verdeeld worden, maar slimmer is het om een systeem te maken waarbij de gebruiker die een hogere temperatuur restwarmte nodig heeft vooraan zit, en de gebruiker die de laagste temperatuur restwarmte nodig heeft achteraan. Zo wordt voorkomen dat warmte van een te hoge energetische waarde verspild wordt bij een functie die deze niet nodig heeft.

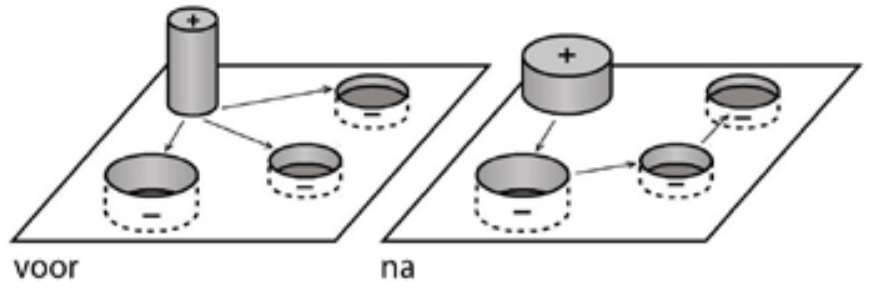

Figuur 2. Een warmtecascadering 
Om bovengenoemde strategieën om te kunnen zetten in integrale ruimtelijke visies is een vijfstappenbenadering ontwikkeld. De stappen zijn achtereenvolgens 1 ) het analyseren van de huidige situatie inclusief potenties voor duurzame energie, 2) het in kaart brengen van kortetermijn ontwikkelingen, 3) het illustreren van mogelijke langetermijn veranderingen, 4) het opstellen van integrale visies op regionaal niveau en 5) het identificeren van specifieke ruimtelijke interventies. Met integraal wordt hier bedoeld dat het winnen, opslaan en transporteren van hernieuwbare energie niet losstaat van andere functies in het landschap, maar juist daarmee wordt verbonden. Zo worden win-win situaties gecreëerd en beschikbare ruimte en energie efficiënt benut. Daarnaast worden alle mogelijke energiebronnen onderzocht op toepasbaarheid in de regio. In plaats van te focussen op één bepaalde, misschien politiek ingegeven, technologie of hernieuwbare energiebron, gaat de vijfstappenbenadering objectief uit van een energiepotentiekaart als basis voor besluitvorming. Deze aanpak is en wordt momenteel in onder andere Zuidoost Drenthe, Zuid Limburg, de Veenkoloniën en Noordwest Overijssel toegepast voor het ontwikkelen van visies op regionaal niveau.

\section{Op naar duurzame energielandschappen}

$\mathrm{Bij}$ het reduceren van de energievraag en het optimaliseren van het winnen, opslaan en transporteren van hernieuwbare energie zou altijd gelet moeten worden op de duurzaamheid van de landschappen die hierbij ontstaan.

De sterke relatie tussen energie en ruimte heeft een wisselende zichtbaarheid gehad in de loop van de geschiedenis. Vóór de industriële revolutie was het duidelijk hoe we de ruimte benutten om onze energie te kunnen oogsten. Het aanzicht en de structuur van grote delen van Nederland reflecteren hoe we energie hebben geoogst en ingezet voor de vorming van ons landschap. In de veengebieden zijn eindeloze dalgronden overgebleven na het afgraven van het veen, een negatief gevolg, terwijl de historische windmolens bij Kinderdijk werelderfgoed zijn en een symbool voor het inpolderen van Nederland. Ook het stadsgezicht van Amsterdam werd voor de industrialisatie gekenmerkt door een groot aantal windmolens.

Tijdens het huidige fossiele tijdperk is impact van energiewinning op de ruimte nog steeds sterk, maar minder zichtbaar voor de burger. Olie, aardgas en kolen worden vaak in afgelegen gebieden in het buitenland gewonnen en deze energie is vervolgens - op enkele centrales en hoogspanningsmasten na - onzichtbaar tot het als elektriciteit uit het stopcontact of als warmte uit de gasleiding komt. Bij de overstap naar hernieuwbare energiebronnen komt energiewinning weer dichterbij. Energie uit zon en biomassa heeft een lagere energiedichtheid dan fossiele brandstoffen. Voor het winnen van voldoende energie uit hernieuwbare bronnen is daarom veel ruimte nodig en een gedecentraliseerd in plaats van een centraal systeem. Dat zal in onze nabije omgeving direct zichtbaar worden, onder andere in de vorm van nieuwe technologie zoals biogasinstallaties, zonneboilers en -panelen en warmte-krachtkoppeling (WKK). Meer indirect kan de energietransitie bijvoorbeeld zichtbaar worden in de oriëntatie van nieuwe gebouwen, die op de zon gericht moeten worden voor een optimale winning van zonne-energie, en in het transport van biomassa naar centrales.

Deze groeiende zichtbaarheid van duurzame energie is niet altijd even positief. Het plaatsen van zonneboilers voor het verwarmen van water lijkt bijvoorbeeld een goed initiatief, maar als ze op de grond worden neergezet kunnen ze concurreren met bestaand landgebruik of biodiversiteit. Het is daarom beter om zonneboilers en -panelen op daken van bestaande huizen en industrie te plaatsen. Ook schoonheid in het landschap is belangrijk voor het slagen van de transitie naar duurzame energie. Het plan om honderd windturbines in het IJsselmeer te plaatsen voor de kust bij Urk heeft tot veel protest geleid. Uiteindelijk, in 2010, is Maria van der Hoeven, de toenmalige minister van Economische Zaken, gezwicht voor de bezwaren van de Urkers. Er komen zeven turbines minder, ter voorkoming van horizonvervuiling en aantasting van het beschermde dorpsgezicht van Urk. Dit is geen op zichzelf staand voorbeeld. Op veel plekken in Nederland ketsen plannen voor windenergie af met de aantasting van de landschappelijke kwaliteit als argument. De veronderstelling is dat wanneer er meer aandacht is voor de impact op het landschap bij het plannen en ontwerpen van projecten, de slagingskans vergroot wordt en daarmee ook duurzaamheid. Een duurzaam energielandschap betekent dus niet alleen dat er hernieuwbare energie gewonnen wordt zonder negatieve invloed op de bestaande biodiversiteit en landgebruik, maar ook dat er geen afbreuk wordt gedaan aan de landschappelijke kwaliteit. In de vijfstappenbenadering wordt voortdurend naar deze criteria toegewerkt en de voorgestelde interventies worden aan het eind van de laatste stap geëvalueerd aan de hand van deze criteria. Voorts ligt het aan het ambitieniveau of ruimtelijke planning en ontwerp de kans krijgen om bij het maken van energievisies hoger in te zetten, en de kans aangegrepen wordt om zelfs verbeteringen op deze criteria te bewerkstelligen.

\section{Ruimtelijke planning en ontwerp zijn disciplines bij uitstek om de energietransitie aan te pakken}

De volgende drie voorbeelden laten zien hoe duurzame energie zichtbaar kan worden in het landschap en illustreren eveneens het idee dat duurzame energie als kans gezien kan worden voor het verhogen van landschappelijke kwaliteit.

\section{Windturbines in de Flevopolder}

In de Flevopolder wordt, zoals bij velen bekend is, op grote schaal windenergie geoogst. In veel gevallen zijn landschapsarchitecten betrokken geweest bij het bepalen van de locatie van windparken. Vanaf bepaalde plekken of wegen is de ontworpen lijn inderdaad 


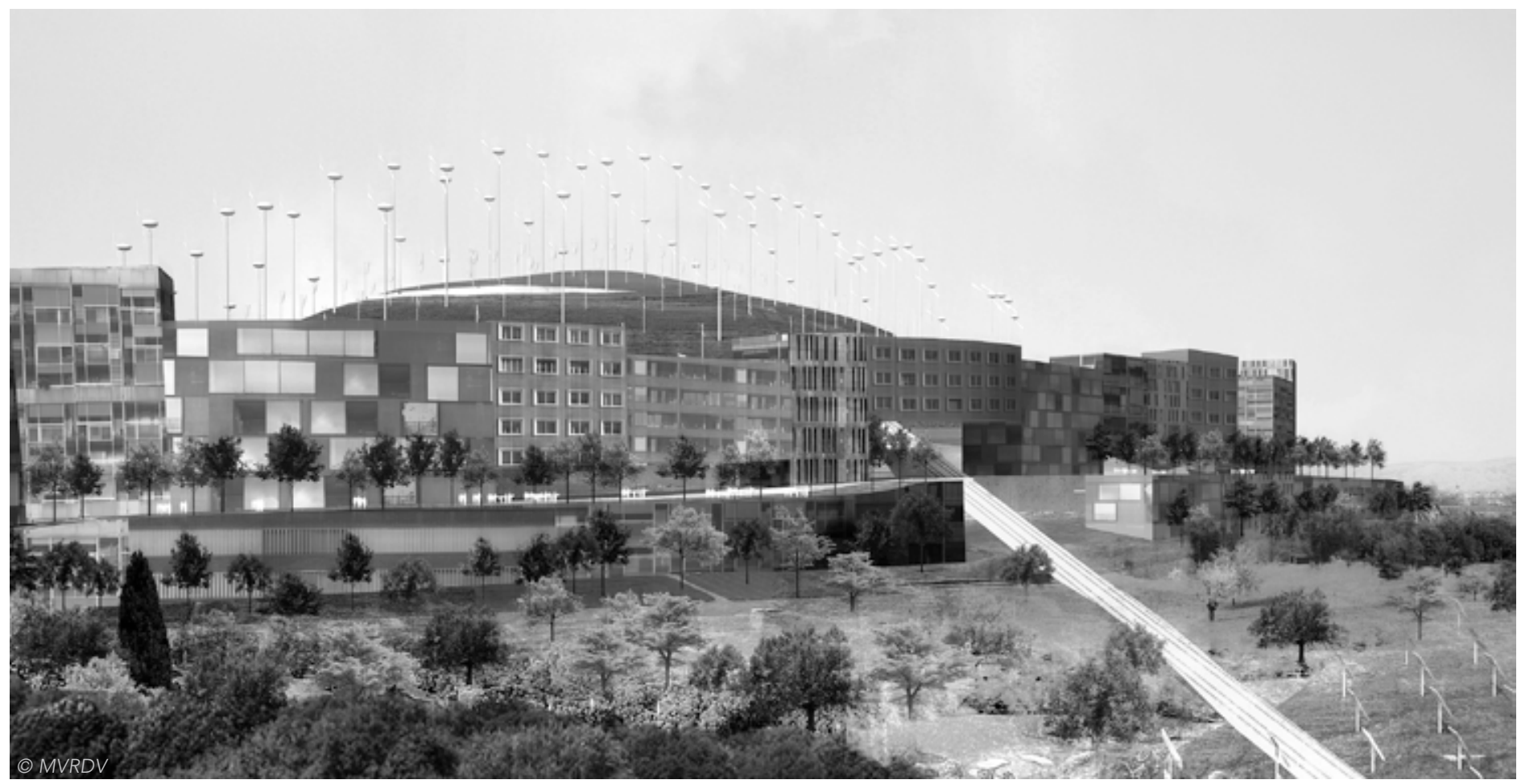

Een impressie van het ontwerp voor de ecostad Montecorvo in Spanje

herkenbaar. Vanaf vele andere perspectieven ontstaat echter vooral een diffuus en chaotisch beeld. Hoe is bij een veelheid van windparken toch de eenheid in een dergelijk landschap te waarborgen? En hoe wordt voorkomen dat de ontwerpen van verschillende parken onderling interfereren? Het plaatsen van windturbines, zowel solitair als in parken, is een lokaliseringsopgave bij uitstek. Maar ook het ontwerp van de turbines zelf kan beïnvloed worden. Krijgt de molen bijvoorbeeld een groene voet, zodat hij wegvalt tegen de achtergrond van een weiland, of moeten we het meer artistiek aanpakken, zoals het windpark Eemmeerdijk in Zeewolde, waar de achttien turbines ieder in een eigen kleur uitgevoerd zijn?

\section{Ecostad Montecorvo, Spanje}

In dit tweede voorbeeld wordt breder gekeken dan windenergie. Het plan voor de ecostad Montecorvo in Spanje betreft een duurzame uitbreiding van de stad Logroño. In 2008 is toestemming gegeven voor de bouw van het project met daarin drieduizend woningen in de sociale sector. In het plan wordt maar 10 procent van het oppervlak van totaal 56 hectare bebouwd. Door een slimme stapeling van de woningen is vanuit elke woning een mooi uitzicht gecreëerd. De ruimte die overblijft wordt vormgegeven als een ecopark: een mix van landschap en energieproductie. Op de heuvels eromheen die op het zuiden georiënteerd zijn, worden zonnepanelen geplaatst om de optimale ligging voor de winning van zonne-energie te benutten. Op de toppen van de heuvels, waar het flink waait, staan windmolens die tegelijk een baken in de omgeving zijn. De opbrengst aan zonne- en windenergie samen is genoeg voor het energieverbruik van de drieduizend woningen. Daarmee bereikt de stadsuitbreiding van Logroño een CO2-neutrale voetafdruk. Het interessante van dit plan is dat de energie-opgave geïntegreerd is in het plannen en vormgeven van een hele stadsuitbreiding en er tegelijkertijd over is nagedacht hoe het ook aantrekkelijk kan worden gemaakt voor de toekomstige bewoners. De ontwerpers hebben dus duurzame energie als middel ingezet om de kwaliteit en schoonheid van de leefomgeving te verhogen. De bouw van het project is van start gegaan, maar het zal moeten blijken of deze doelstelling bewerkstelligd wordt.

\section{Een duurzaam energielandschap betekent óók dat er geen afbreuk wordt gedaan aan de landschappelijke kwaliteit}

\section{Identiteit en schoonheid}

In de tweede innovatieregeling van de het programma 'Mooi

Nederland', waarin 'Identiteit van energielandschappen' één van de drie thema's was, wordt energietransitie als een kans gezien voor het creëren van extra identiteit en schoonheid in een gebied. Gemeenten en andere initiatiefnemers konden in 2010 hun plan indienen om bij te dragen aan de zichtbaarheid van duurzame energielandschappen en integratie van energietransitie met de fysieke omgeving. In totaal zijn veertien projecten binnen dit thema gehonoreerd. In het bepalen van landschappelijke kwaliteit speelde het begrip 'identiteit' een sleutelrol, en het bleek dat de inzendingen daarmee goed uit de voeten konden. In de plannen waarin biomassa een 
belangrijke rol speelt, draagt energietransitie bij aan het in stand houden van bijvoorbeeld een coulissenlandschap (in de inzending 'Energie Marke Haarlose Veld') of een houtwallenlandschap (in 'Duurzame energiewinning uit het Nationaal Landschap Noordoost Twente' en 'Groen Goud uit landschapsonderhoud'). Biomassareststromen worden benut om landschapsonderhoud te financieren en daarmee kunnen gewaardeerde landschapselementen, bepalend voor de identiteit van deze landschappen, veiliggesteld worden. In andere projecten wordt bijvoorbeeld onderzocht hoe duurzame energie zich laat combineren met toerisme ('Beleef het op GoereeOverflakkee') of hoe duurzame energie stadsranden kan definiëren ('Energieke integratie stad en landschap'). Ook bij deze voorbeelden zal de praktijk uit moeten wijzen of energietransitie inderdaad als een kans voor het verhogen van landschappelijke kwaliteit gezien kan worden: een veelheid aan plannen en onderzoek is inmiddels in uitvoering

\section{Conclusie}

Al eerder is, bijvoorbeeld in AGORA 2007-5 'Energie', betoogd dat ruimtelijke ordening en ontwerp energietransitie kan ondersteunen en sturen. Recent onderzoek hiernaar bracht nieuwe strategieën en aanpakken naar voren, zoals de besproken vijfstappenbenadering. Binnen het bredere kader van duurzame energielandschappen is het vooral belangrijk dat de criteria rond concurrerend landgebruik, biodiversiteit en landschappelijke kwaliteit vanaf een vroeg stadium meegenomen worden. Landschappen waarin slechts hernieuwbare energiebronnen een plek hebben gekregen, zoals veel van de huidige windturbineparken, zijn nog geen duurzaam energielandschappen, alleen al omdat ze als visueel hinderlijk ervaren worden. De interesse voor de zichtbare consequenties van energietransitie en de zorg voor behoud van landschappelijke kwaliteit zijn, met uitzondering van het debat rond windenergie, vrij recent. Uit de voorbeelden volgt dat energietransitie niet alleen een doel op zich is, maar dat het door de ruimtelijke ordening zowel als middel en als kans wordt opgevat voor het verhogen van landschappelijke kwaliteit en daarmee duurzaamheid. Hoewel er is verzaakt om een goede

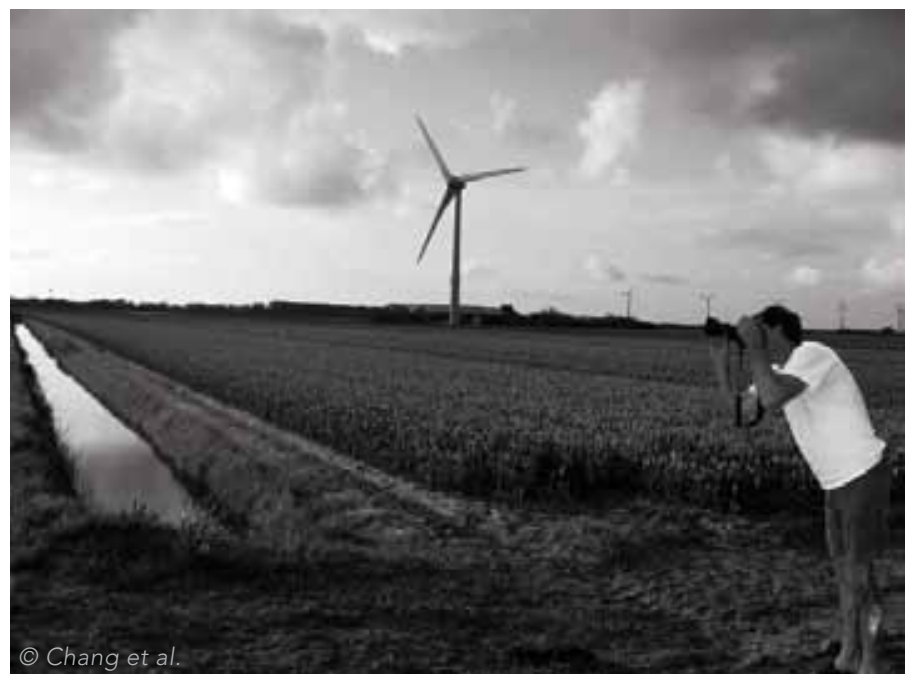

Een mogelijke combinatie van toerisme en duurzame energie op Goeree-Overflakkee definitie van landschappelijke kwaliteit te geven, dat is een nieuw onderzoek en discussie op zich, maken begrippen als 'schoonheid' en 'identiteit' hier duidelijk deel van uit.

Het besproken project van de ecostad Montecorvo en de veertien met subsidie gehonoreerde projecten van het innovatieprogramma 'Mooi Nederland' zijn momenteel volop in uitvoering. De toekomst moet uitwijzen of het streven naar meer schoonheid en identiteit inderdaad bewaarheid kan worden.

Renée de Waal (renee.dewaal@wur.nl) is landschapsarchitecte en doet onderzoek naar duurzame energielandschappen en ruimtelijke kwaliteit. Zij is als promovenda verbonden aan de leerstoelgroep Landschapsarchitectuur aan Wageningen University. Sven Stremke (sven.stremke@wur.nl) werkt als universitair docent en landschapsarchitect bij dezelfde leerstoelgroep.

Dit artikel is deels gebaseerd op een presentatie tijdens de sessie 'Identiteit van Energielandschappen' bij de bekendmaking van gehonoreerde projecten van de innovatieregeling Mooi Nederland, op 4 november 2010 in IJsselstein.

\section{Literatuurselectie}

Kann, F. van (2007) Energieneutraliteit als een ruimtelijke kwaliteit. AGORA 2007-5, pp. 8-12.

Koh, J. (2005) The energetic strategy of ecosystem development and urban/ regional spatial restructuring and regeneration. In: F. van Dam en K. J. Noorman (eds.) Grounds for change: bridging energy planning and spatial design strategies. Groningen: Grounds for Change. Ministerie van Infrastructuur en Milieu (2011) Identiteit van Energielandschappen. https://kennispleinmooinederland.vrom.nl/ themas/ruimtelijke_kwaliteit/identiteit_van_energielandschappen (05/05/2011)

Ministerie van Infrastructuur en Milieu (2011) Mooi Nederland evenement 2010 - de winnende projecten. https://kennispleinmooinederland.vrom.nl/activiteiten/2010_november_mooi_nederland_evenement_2010 (05/05/2011)

MVRDV (2011) Ecocity Montecorvo. http://www.mvrdv.nl/\#/projects/ greenlightforecocity (05/05/2011)

Sijmons, D. (2008) Kleine Energieatlas. Ruimtebeslag van elektriciteitsopwekking, Den Haag: Ministerie van VROM.

Stremke, S. (2010) Designing sustainable energy landscapes. Concepts, principles and procedures. Wageningen: Wageningen University (proefschrift)

Stremke, S. en J. Koh (2010) Ecological concepts and strategies with relevance to energy-conscious spatial planning and design. Environment and Planning B: Planning and Design 37, nr. 3, pp. 518-532. Stremke, S., A. van den Dobbelsteen en J. Koh (2011) Exergy landscapes: Exploration of second-law thinking towards sustainable landscape design. International Journal of Exergy 8, nr. 2, pp. 148174

Stremke, S. (2007) Ontwerpen aan energie autarkische regio's. AGORA 2007-5, pp. 12-16 